\title{
CHANGING LEARNING LANDSCAPE: FROM CAD TO BIM AND BEYOND
}

\author{
DAVID EDWARD MORTON ${ }^{1,2}$ \& IGNASI PÉREZ ARNAL ${ }^{1,2}$ \\ ${ }^{1}$ Department of Architecture, Northumbria University at Newcastle, UK \\ ${ }^{2}$ BIMAcademy.es, IBIMA, Spain
}

\begin{abstract}
This study considers how and when students actively move between analogue (traditional), and digital methods (CAD/BIM) of design exploration. It maps the design process to explore how traditional methods with the convention of abstraction are becoming intermixed with the opportunities of synthetic simulation, via digital methods, during the students' design process. The studies original contribution to knowledge focuses on a deeper understanding of how and when analogue and digital methods are used in the design process, collated to design out comes. It is, foremost, the first study in this subject area to analyse the use of CAD and BIM in parallel with traditional methods of abstraction and simulation in the design process.
\end{abstract}

Keywords: computer aided design, building information modelling, design process, academia, learning.

\section{INTRODUCTION}

The use of CAD/BIM in the design process allows the opportunity to query the roles and rules of the traditional architectural conventions of visual communication. The universal use of two-dimensional, orthographic projection has become the universal tradition conventions of visual communication which are now understood by contemporary architects originated in the fifteenth century [1]. The increasing use of digital methods, such as CAD, being used in the design process are now changing both drawing conventions and the very design process itself. Extant literature suggests recognises that there are cognitive processes that run concurrent with activities that can consciously and subconsciously aid or inhibit the design process [2].

In the modern era, with the invention and subsequent use of digital technologies, the design process has become even more difficult to conceptualise and define. Therefore, students of design subjects are even more likely to find it difficult to navigate through their design process to a successful outcome. Educators are not always equipped to help, having often been educated to use analogue methods [3]. There is thought that designing on the computer may involve different cognitive processes to that of analogue methods [4]. It has been argued that the computer has aided an architect's ability to operate creatively [5] others are far less positive, especially in the educational environment. McVie and Paton-Walsh [6] referring to a study undertaken in the US, concluded that students found it 'far more difficult and less interesting to learn from the screen than through analogue methods, such as drawings and physical model making'. It is therefore difficult to fully comprehend the impact of the computer on the design process generally. The computer undoubtedly speeds up certain activities, especially those that are repetitive, while there is a suggestion that the computer may inhibit the creative process required to advance a design project [7]. Designing is very specific activity that resides within concepts of praxis. In theoretical terms, praxis is our capacity to analyse ideas, apply, make and develop them, while simultaneously reflecting as we are doing. In an educational setting, this natural way of thinking and doing is considered vitally important, especially within the creative disciplines. The effects that the computer has 
on design-specific praxis have not yet been considered in any depth in extant literature. However, what discussion there is suggests that it may well disrupt this natural process.

It has been argued that existing Computer Aided Design (CAD) packages were not conceived for designing in a learning environment (or operating creativity) but are aimed at professional practice as a production tool [8]. The use of such 'production tools' results in good design skills being replaced with good computer skills [9]. This is despite the word design appearing in the title (CAD). This type of software is extremely powerful and persuasive and there is concerned raised by educationalists that if it is introduced too early in an architect's education, or at the wrong stage of a project, then it could inhibit the design process thus resulting in a more linear approach to designing, or negating opportunity to develop complex design ideas [10]. It is also recognised that a students' creativity is often limited to their knowledge of the software with those who can exploit the software's full potential tend to operate more creatively than those with limited knowledge. In this case the possibilities and the potential of praxis is very much constrained by an inability to properly use the computer.

In summary, the extant research on the use of CAD/BIM in the design process is focused on skills and activities within that are or have been augmented by the use of CAD/BIM. When considering the use of $\mathrm{CAD} / \mathrm{BIM}$ in the architectural design process the extant research is considerably smaller in scale and written by a limited number of researchers, some of which have been noted in this chapter. Therefore, this study will observe and map the entire design process of a randomly selected group of students, in order to understand how and where $\mathrm{CAD} / \mathrm{BIM}$ activities occurred and what are the effects of CAD/BIM being exploited in these design processes. Potential patterns and occurrences will then be categorised and assessed in order to suggest a digital framework to tutors teaching in this subject.

\section{IMPLEMENTATION OF CAD AND BIM INTO ARCHITECTURAL EDUCATION}

The perception of CAD as merely a tool to be used in architectural design remained a persistence conviction, previously Friedman [11] posited that to consider CAD as a tool was to undermine the additive skills and conceptualisation advantages of working with an intrinsically accurate digital model. More recently, in Shelbourn et al. [12] studied students' perceptions of BIM education, finding that frameworks in degree programmes focused only on using computer technologies to teach modelling for visualisation within the architectural discipline, they did not consider possible wider advantages, such as using BIM for design collaboration with the other disciplines.

The traditional method of visualisation for a proposed design is through abstraction, in plan, section and elevation. The use of CAD realigns these conventions, displacing Schöns theory of the 'critical practitioner', creating visualisation of a design that addresses the complexities and simultaneities of the design solution in parallel. Knowledge of the design solution becomes displaced, with CAD simultaneously offering detailed visualisation at multiple levels of scale, thus increasing the opportunity to gain a richer understanding of the design problem and therefore potential solution.

When considering CAD and its impact on the design process early research of Lawson [13] with recent research of Taleyarkhan et al. [14] suggested that using CAD in the design process requires an understanding of how it impacts on the learning of a student. Lawson deemed the use of CAD, now over two decades ago, as a new and interesting discourse in the academic architectural studio, with the 'CAD tool' being the new exploration methodology. Taleyarkhan et al. [14] paralleled the proposition determined by Lawson [13] that to understand the impact of CAD on the design process was critical in its successful application 
within academia. Findings of Taleyarkhan et al. [14] suggest that the use of CAD achieves a significantly increased understanding of the design problem and subsequently it's potential solution. Therefore, CAD offered greater levels of detail to be perceived in a dimensionally accurate virtual model. The traditional conventions of communication as we know and understand it in the academic architectural studio of two-dimensional sketching requires abstraction and representation of the design as opposed to the CAD model allowing direct presentation.

When CAD is used the architectural intent can be visualised in three dimensions in both form and space. The communicative potential of CAD to visualise and understand a design solution realigns the traditional methodology of abstraction and representation displacing this to literal re-presentation of the complete (virtual) design model. The use of CAD within the design process establishes displacement of the traditional abstraction methodology. It creates discrete and fragmented representation, into a singular modelling convention allowing convergence between abstraction, literal representation, and simulation of the design. Extant literature suggests that traditional analogue method of sketching and manual model making in the design process is increasingly becoming replaced by the tacit convention of using CAD and as such requires a revision of the traditional methodologies used in architectural academia.

Research completed by Abdirad and Dossick [15] suggested caution noting that BIM allows far more power to assess the design, but in parallel also created a dependency on the software itself and additional time investment required in learning software. The research outcomes suggested that the designer would evolve into merely an operator, with the dumbing down of the creative process becoming the sceptical outcome. Ambrose [16] advocated that the studio structure of our architectural schools and curriculum needs to be redeveloped around the innovative approaches of BIM. Furthermore, Ambrose and Fry [17] conclude that BIM must become integrated within all design taught modules. Ambrose championed the instantaneous testing of design solutions using BIM allows a richer understanding of design solutions in the design via exploration of the virtual building model. His studies indicated that analysis in the design process using BIM would develop skills, not hinder them, and remove the concern that other academics and researchers have of students becoming mere operators of BIM.

Despite there being a large increase in the number of publications on the subject of Building Information Modelling (BIM), there remains a lack of critical review in the implications of BIM on the design process undertaken by architectural students. Therefore, this study intends to understand the 'how' and 'when' of using CAD in the design process. From this analysis it is proposed to create an informed digital framework suggesting an updated methodology for use of CAD in the academic studio context.

\section{METHODOLOGY}

This study presents rich data based on the immersion of the researcher in the everyday lives of master degree architecture students and proposes a series of recommendations addressing these via the development of a digital framework to be used in teaching within the architectural studio. The data was collected through weekly interviews with each student. The observation of their design processes included a review of their submitted work at each monthly design review over the entire final academic year (a period of nine months). This collection of data amounted to over 600 interviews and 48 design review submissions being analysed in order to understand the impact of CAD/BIM on the design process. The methodology of this study encompasses the 'rationale and the philosophical assumptions that underlie a particular study' [18]. Therefore, the methodology of a research project very much 
informs the research methods that are used to determine the research design (collection, analysing and interpreting of data) and investigate the initial question of the research, in this case, to understand the impact of CAD/BIM on the design process. As such the researcher must decide upon the structure of the research methodology and formulate the adopted research strategy in a way that is in accordance with the aims and objectives of the study whilst, at the same time, ensuring retention of an original contribution to an existing body of knowledge [19].

This research employed a combination of inductive and deductive analysis in its approach. The early stages of the research used deductive analysis within the literature review, "as the literature review helps provide a source for the focus of the research" [20]. The literature review exploited research publications from journals and conference proceedings and provided an understanding of historical and current research in the field of architectural design process including methods used within these processes (analogue sketching and modelling making to more current use of CAD and BIM).

\section{THE STUDY}

The approach taken in this research was a case study involving 16 Masters Architecture Degree Level students in their final year of study. Semi-structured interviews were undertaken over the longitudinal study period of 9 months, leading to over 600 interview records. Data generation methods included interviews, observation, and document review, while themes were inductively generated through thematic analysis. Bourdieu's concepts of field and habitus were used to guide the conduct of the study and interpretation of the findings. The study indicates that it is both desirable and often necessary for a student to use a blend of analogue and digital techniques in the presentation and representation of their design project. However, it must also be cognisant that an over-reliance on digital methods in the design process for visualisation can distance the student from the physical realities of the actual design. This thesis does not argue for one position over another, instead it endeavours to understand the use of both analogue and digital methods and determine how both can be used in conjunction to aid the student in their design process.

The researcher chose final year masters architecture students, with several years' design experience of using both analogue methods of design exploration and the computer. This approach afforded the study the ability to observe students who were less CAD/digitally inhibited due to their knowledge of the software and allowing for more consistency across design process and methods used and reducing the impact of these variables within the research. These students were chosen randomly from the year group who all had similar design training, this included a mix of analogue and digital approaches within their design process. The design processes of all 16 students studied were thoroughly mapped across the academic year. From this inquiry, the research observed patterns and similarities in the practice, considering amongst other questions:

- When the students start to use the computer?

- How is the computer used?

- When the computer offers advantage in the design process?

- When are the students are using the computer incorrectly?

- What impact the computer has on the traditional analogue methods?

- Can the computer lead to creative insights?

- Does the computer inhibit the creative design process? 


\section{THE FINDINGS}

At the culmination of the case study the students sketch books and design projects were analysed in detail. The design work was assessed for use of analogue or digital activities used in design problem resolution and mapped to the interviews that took place during the design process. For the 9-month duration of the case study, a weekly interview with each student was undertaken to capture data that would facilitate the final assessment of the overall design process. This data allowed the alignment of commentary between student and tutor, observations made during tutorials and general observations made on modes of design inquiry (analogue or CAD/digital).

\section{OVERALL IDENTIFICATION OF THEMES IN DESIGN PROCESS}

At the culmination of the case study the students sketch books and design projects were analysed in detail. The design work was assessed for use of analogue or digital activities used in design problem resolution and mapped to the interviews that took place during the design process. For the 9-month duration of the case study, a weekly interview with each student was undertaken to capture data that would facilitate the final assessment of the overall design process. This data allowed the alignment of commentary between student and tutor, observations made during tutorials and general observations made on modes of design inquiry (analogue or $\mathrm{CAD} /$ digital).

\subsection{Identification of themes: All students - Month 1}

During the first month of the students' design processes all of the students within the study undertook site and contextual analysis. These studies included exploration of their proposed site via sketching or making models in order to process their design approach and formulate initial ideas. The sketchbooks from this period mainly contained initial thoughts of proposed schemes without yet commenting or understanding where this analysis made lead them.

All 16 students studied undertook site context and historical research to establish their thesis area. Activities used during this analysis mainly consisted of sketching, modelling, and assembling data from various sources, such as digital maps. In addition to general information gathering, physical modelling was used to explore and record initial design thoughts that were yet to be refined. The use of physical models gave the students the opportunity to gain a better understanding of their site without knowing the consequences and final outcome of these initial design decisions. These models were a mixture of semiaccurate site and context models or in some cases more conceptual in form.

Students refined and amended these models in a reflective act during this stage of the design process. The models afforded the students the ability to consider contextual issues and generate initial design ideas to develop further. These initial studies became a constant source of reference for the majority of the students in the study being continuously revisited during months 2-8 prior to the final month of production activities in readiness for the final submission of their design projects (month 9).

When assessing the use of CAD against matching cases within the data during month 1 of the study the findings indicate that 14 of the 16 students undertook no CAD during this period of their design process. When this data was further analysed, those students completing more analogue tasks were focused on understanding the design problems that their brief would need to meet as they began to formulate their initial design brief. When reviewing the two outlying students in this data query, the tasks undertaken one student remained focused on understanding the overall design problem and their development of the design brief. The remaining student, only 1 from the 16 students studied used CAD from the 
outset of their design process, however shared the overall aim of focusing on the development of the design brief by understanding the design problems that their brief would need to meet. These findings are shown in Fig. 1, in which the use of analogue methods used for understanding or defining the design problem can be seen to be significant and CAD use is comparatively very low.

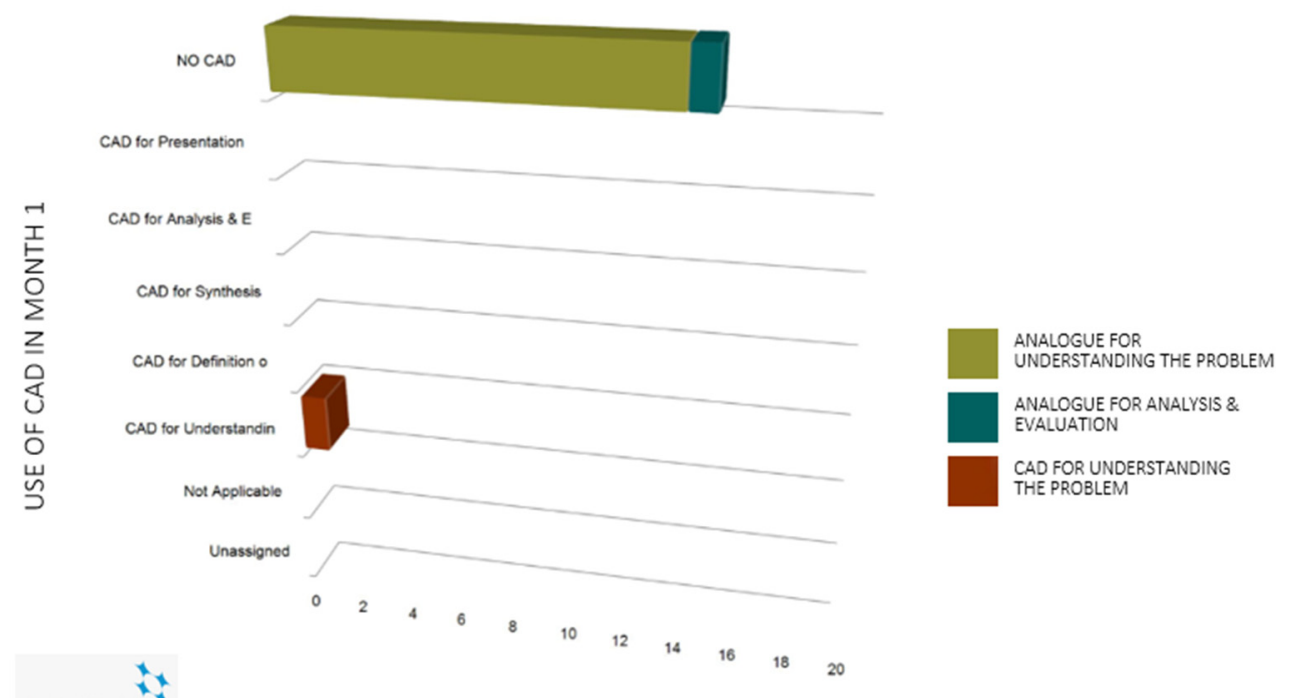

NUMBER OF MATCHING CASES WITHIN STUDY

Figure 1: Comparison of CAD and analogue methods used during month 1.

\subsection{Identification of themes: All students - Month 2}

The design processes of the students studied during month 2 generally followed a period of focused enquiry. The activities used by each student began to differ during this month, however, the overall focus remained the development of initial site responses and how these could be used to develop the design brief. Students who began to use CAD to model their proposed site, such as $\mathrm{S}-2 \mathrm{C}$ and $\mathrm{S}-8 \mathrm{H}$ to create $3 \mathrm{D}$ models of their sites to assess, reflect upon and illustrate routes through and around their chosen sites. The level of data within these digital site models varied, with student $\mathrm{S}-8 \mathrm{H}$ also adding his analysis of the building heights, as this aspect was deemed important to his building's contextual response. Fig. 2 shows 10 of the 16 students retaining a purely analogue approach to their design process. The remaining 6 students used digital methods to understand and reflect upon their design choices in order to define the design.

All students began to increase analysis of their chosen site and surrounding context to begin to 'problem set'. Those students who continued to use analogue approaches (physical models) photographed these physical models in order to create generative sketches and complete diagrammatic outputs that summarised their analysis of the brief and site.

When creating a query of CAD use during month 2 of the study the findings indicated a continued non-CAD approach, with 10 of the 16 students using analogue methods in their design process, these included sketching, painting and photography in the recording of their 


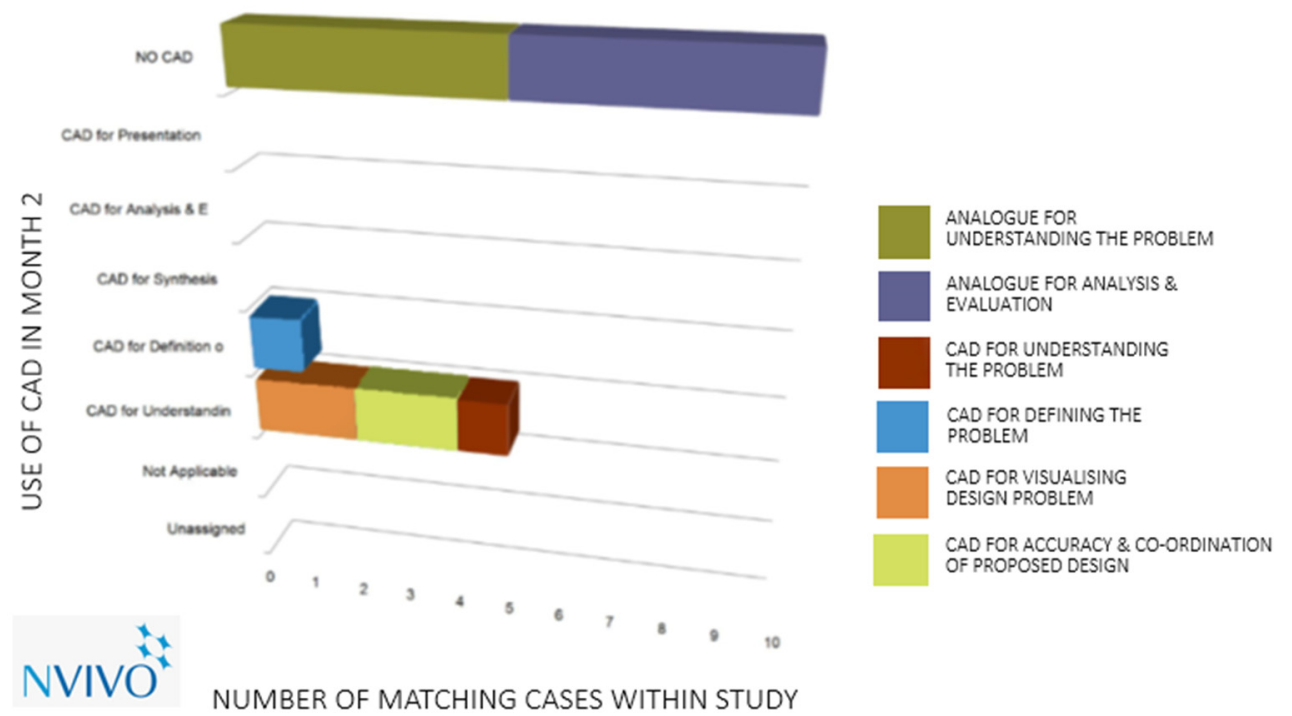

Figure 2: Comparison of CAD and analogue methods used during month 2.

proposed sites. The remaining 6 students began to use CAD during month 2. Just one student used CAD to begin to define his design brief and initially analyse the design of his proposed scheme. The remaining five students continued to refine their understanding of the site and proposed scheme by resolving their initial design brief proposals. These findings were further queried and established that within this sub-group of five students, two students used analogue methods in parallel to CAD to refine their design brief and two used analogue methods in parallel to CAD to increase definition of design brief proposals. The remaining student used CAD to collate numerous maps of their site in order to create historical overlays of the site and its development. The historical mapping of the site allowed them to refine their design brief.

In month 3, the students were exclusively focused on activities that informed concept development that reinforced initial thesis proposals and developing the design brief. Digital models of sites completed during the initial 2 months were now used to produce basic renders of sites onto which analysis of routes, levels or other significant contextual features were added in editing software to use in design brief documentation. This month was a period of focused research that consolidated analysis into initial drafts of design briefs. The students who had used solely analogue activities up to this stage in their design process spent considerable time during this month drawing and diagramming their findings in order to present site analysis at the monthly design review.

During this month of the study, the students began to take divergent routes in their design processes. Five of the students began to use digital models to gain a greater comprehension of the surrounding site topography. The example shown in Fig. 3 shows how student S-2C modelled her site and surrounding buildings to a high level of detail. The student geo-located her digital model in order to accurately plot the sun path around the site. The shading analysis from this exploration was used to inform her design brief. Further abstract studies were carried out this month by student $\mathrm{S}-2 \mathrm{C}$ to develop the design brief in response to findings from the digital modelling. These combined activities were used to conclude her response to 
context and inform the next phase of the design process. Fig. 3 depicts the reduction in analogue methods in the design process, with 8 of the 16 students retaining only analogue methods to define design problems. The increase in CAD activities occurred in the synthesis stages of the design process ( 1 student), with the remaining students continuing to use CAD for definition and increased understanding of their design choices.

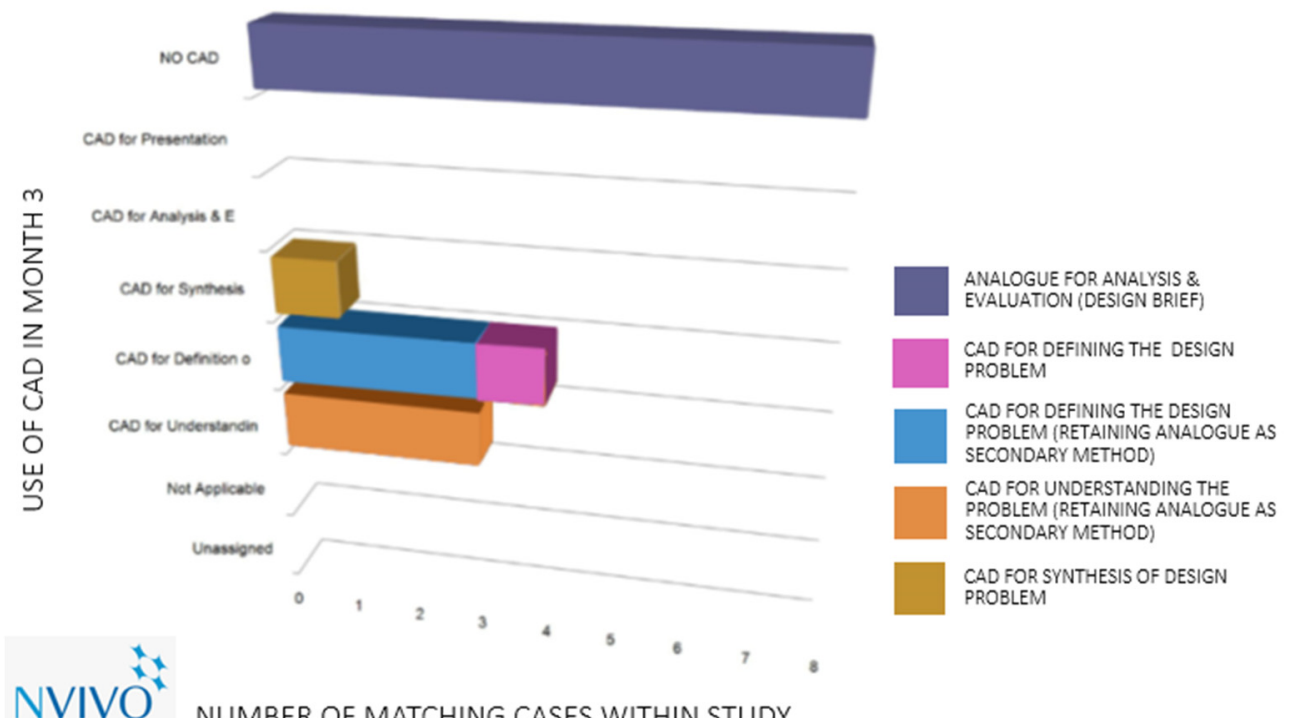

Figure 3: Comparison of CAD and analogue methods used during month 3.

\subsection{Identification of themes: All students - Month 4}

During month 4 the majority of students studied reached a point in the development of their design proposals where the spatial adjacencies and overall form of the building was beginning to become established. Using the digital models, the students began to assess their design brief in parallel with the site context to confirm how these related to the contextual constraints. The nine students who had been using CAD in parallel to their analogue activities during their process, now solely used the CAD models to check for constraints that may impact on their design iterations. This group of students seemed to possess a confidence in their decision making that emanated from the accuracy by which they could 'test' these site conditions.

During month 4 the data reveals that the majority of the students studied moved into synthesis and definition stages of their design process, with 12 of the 16 students focusing on these tasks. From this sub-group, 5 of the students used both CAD and analogue methods in the synthesis stage of their design process. Those students who were employing analogue approaches to synthesis in their design process, were also using CAD in parallel to accomplish definition of their design solutions. Just one student in the group studied focused on solely using $\mathrm{CAD}$ in during their definition stage of their design process during this month. In Fig. 4 the continued increase of CAD was observed in month 4, with only 2 of the 16 students retaining solely analogue approaches to their design process. 


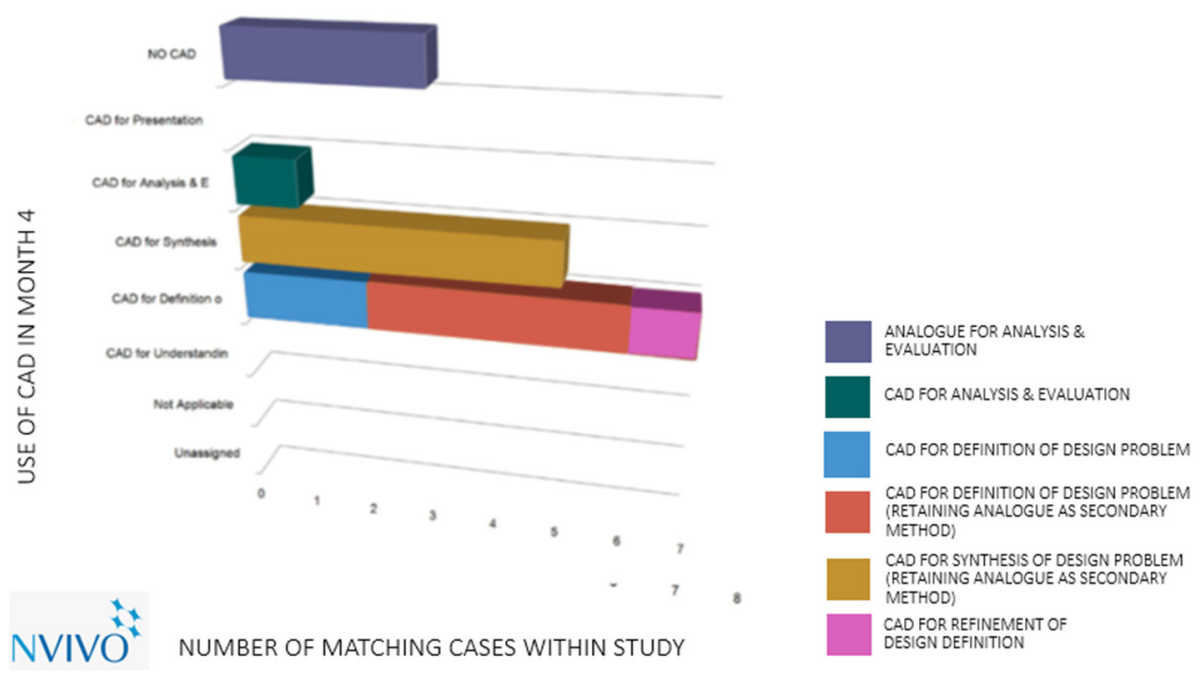

Figure 4: Comparison of CAD and analogue methods used during month 4.

\subsection{Identification of themes: All students - Month 5}

During month 5 the students design processes became increasingly diverse in terms of the activities used in design exploration. The examples shown in Fig. 5 shows how developed the building form is for student S-8H (a tower block) when compared to the students (S-4B and S-5J) design development where form finding was still ongoing. However, this finding from the case study requires further contextualisation, as the design of student $\mathrm{S}-8 \mathrm{H}$ did not develop from this architectural form for the next 2 months (Months 6 and 7) and seemed almost 'fixed' in comparison to student S-5J. The design process of student S-5J used analogue and digital activities cyclically throughout the majority of the 9-month period, he was not fixed to a solely digital approach and developed his scheme to a higher level of detail than student $\mathrm{S}-8 \mathrm{H}$ by month 8 .

The findings indicated that CAD use during month 5 of the study converged on the synthesis stages of the design process for the majority of the students studied. During month 5 , four students used only analogue methods in the synthesis stage of their design process. When considering the 8 students using CAD methods in the synthesis of their design, the data also indicates that these students also used analogue methods in parallel to CAD. The comments made by this group students suggests that CAD was used as a approach to gain increased accuracy to this period of synthesis in terms of scale, dimensional co-ordination and spatial planning of their proposed schemes. The data also indicates a small but continuing trend to retain analogue methods in analysing and evaluating design solutions but retain CAD as a parallel method to synthesise these solutions. In Fig. 5 the students in the study focused on synthesis in their design process using analogue (3 students) and digital methods (8 students) in their design process during month 5.

\subsection{Identification of themes: All students - Month 6}

In month 6 many students focused on the architectural form and materiality of proposed schemes. Those students using analogue activities in their design processes increased 


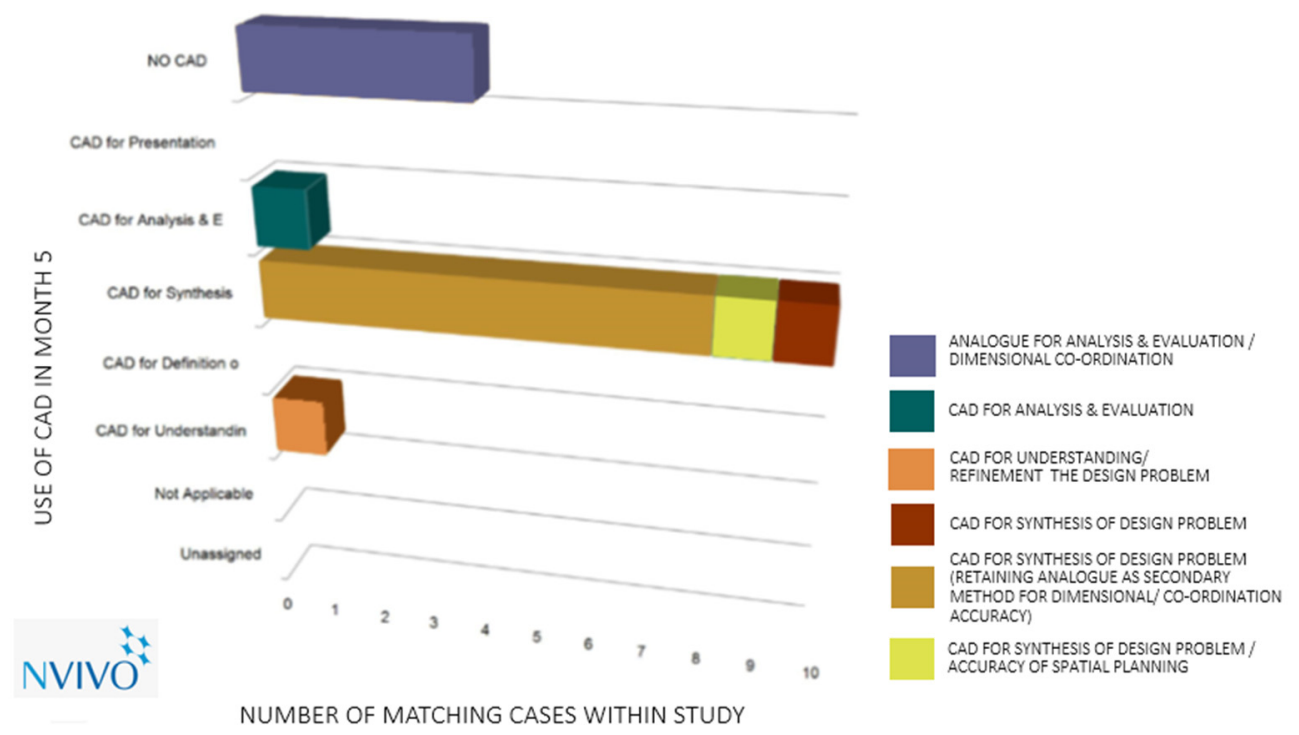

Figure 5: Comparison of CAD and analogue methods used during month 5.

physical model making and began to vary the scale and abstraction of these models in order to explore form for the external envelope or cladding for their proposed schemes. The physical model making brought together previous design ideas merging these into a more refinement of schemes. Those students within the study who used digital activities during this period also undertook to explore external forms and the design of the envelope of their schemes. These digitally driven explorations were undertaken in the virtual environment, using geolocation of models in order to accurately assess sun path, shading, and environmental inquiries.

When assessing the data from month 6 of the study it was apparent that the students were focused on analysing and sythesising their design solutions. Although there were two outlying students, the majority of the group continued to pursue analysis and synthesis in their design process. The findings also indicate the continued trend to use both analogue and CAD methods in parallel during the same design stages. During month 6 , six of the students studied used analogue and CAD methods for the same design stage of analysis and evaluation in their design process. The data for this month also indicated a continued trend to use analogue methods in a specific design stage together with CAD methods in a complementary approach for another design stage. An example of this were the 4 students who used analogue methods in their analysis and evaluation stages in parallel to using CAD to synthesise the design solutions. During month 6 the significant focus in the design process was analysis and synthesis of design ideas as students refined and reflected upon each design decision. The findings indicated that CAD was the primary method of analysis and synthesis for 1 student. The use of analogue methods of analysis and synthesis was used by 14 students. This suggested that the majority of the students in the study retain analogue methods as the primary method of design exploration at this point in the design project, see Fig. 6 . 


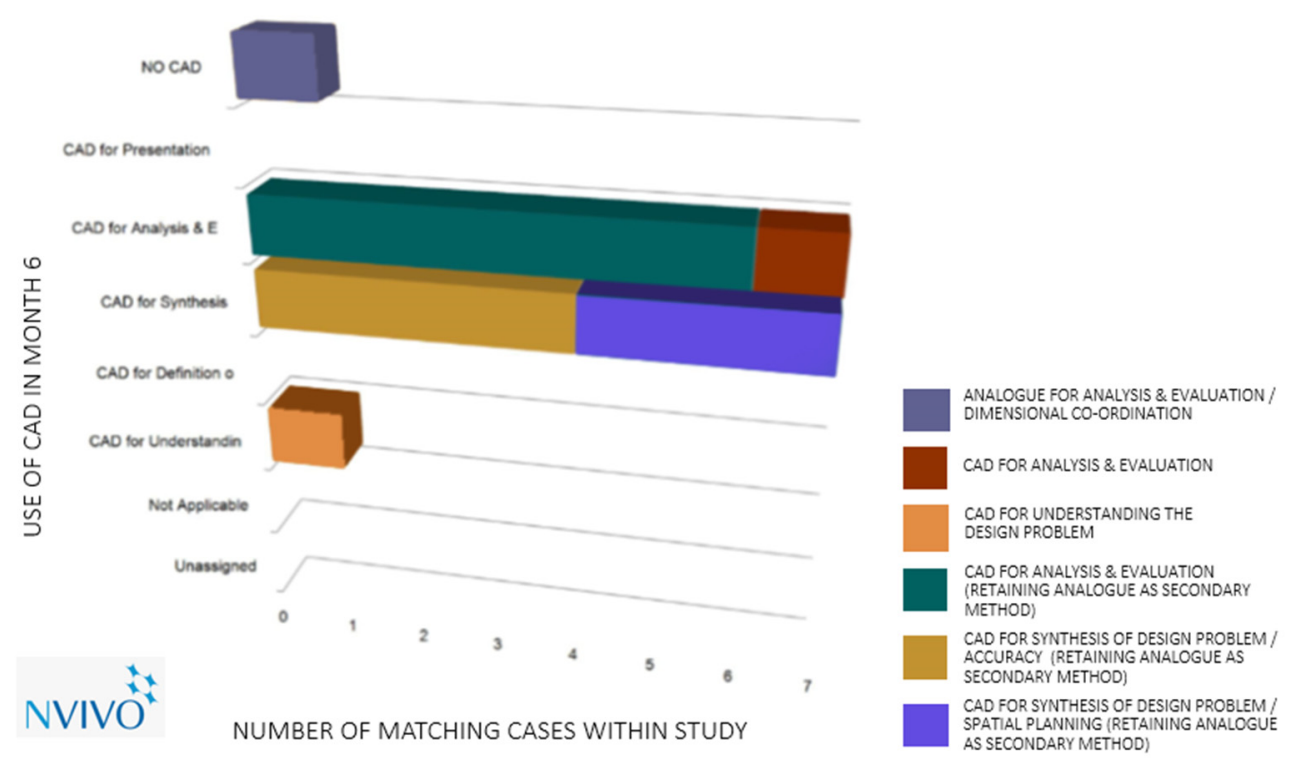

Figure 6: Comparison of CAD and analogue methods used during month 6.

\subsection{Identification of themes: All students - Month 7}

During month 7 the students studied continued to focus on design progression by undertaking activities that moved the space, form, and initial plans of schemes into more formalised and c coordinated plans, sections and elevational proposals. These aspects were refined over this month. The higher achieving students included displacement activities that afforded further design exploration and testing, such as physical and digital model making. Students S-1J and $\mathrm{S}-5 \mathrm{~J}$ began to increasingly oscillate between analogue and digital activities to refine design solutions, with each iteration now occurring at a focused and refined level. By the end of the seventh month of the study the proposed design projects of the student group were becoming increasingly resolved.

The data indicates a very focused period for the group who's design processes were now focused on analysis and evaluating their proposed designs. The findings indicated that 11 of the 16 students remained in a reiterative loop of amending and re-assessing their design ideas and refining design solutions. The trend of retaining both CAD and analogue approaches in parallel can also be seen in Fig. 7. This confirms the use of analogue and CAD methods for the same design stage, analysis and evaluation. When relating this finding to the discussions with the students the use of CAD at this stage seemingly gave the students the advantage of both rapid and accurate testing of design ideas (see Fig. 7).

\subsection{Identification of themes: All students - Month 8}

The findings in the study for students during month 8 indicated a significant increase in the use of digital activities in the design process of all students' sub-groups. The analysis of the design processes indicated that these students oscillated between analogue and digital activities during this month continuing to use both activity modes during final design 


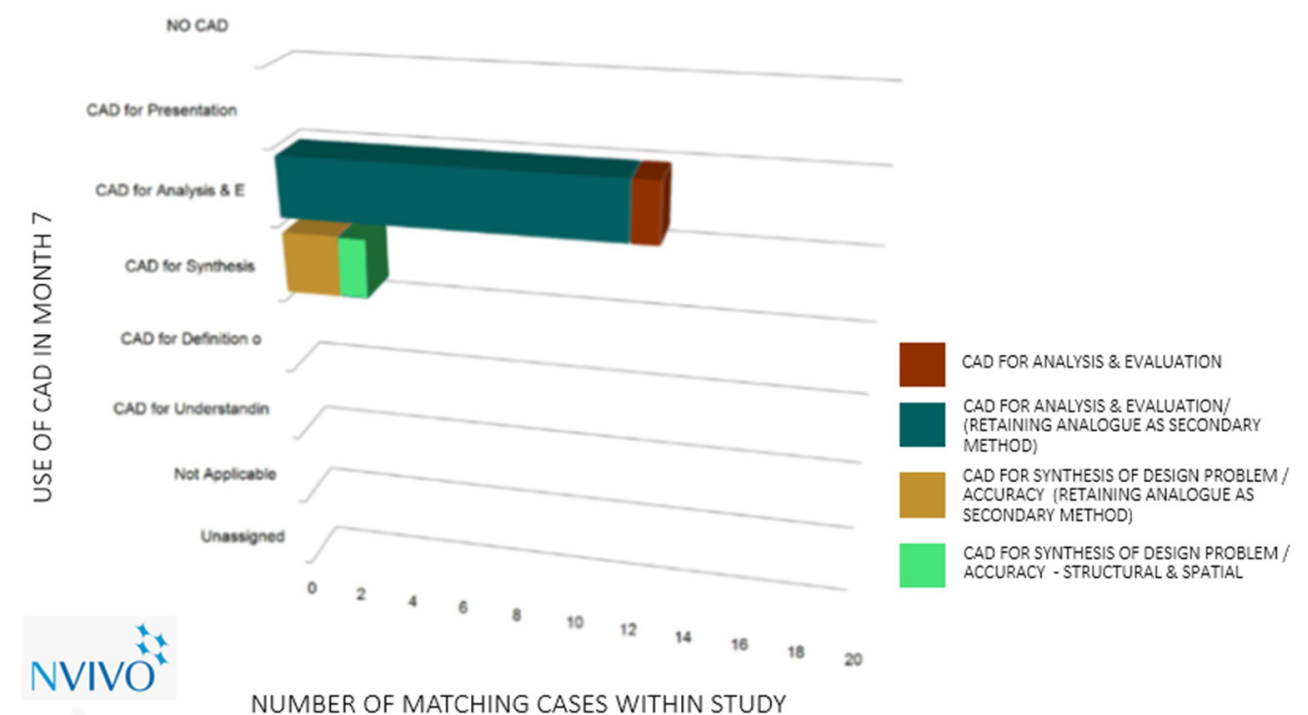

Figure 7: Comparison of CAD and analogue methods used during month 7.

resolution of schemes. The findings also indicated that those students who focused mainly on using analogue activities in months 1 to 7 began to significantly increase use of digital activities during this month. When this increase of digital activities was examined, the findings suggested that the majority of students used digital activities to rapidly test design solutions and increase levels of accuracy and detail in proposed schemes.

As the study moved into the final two months of the overall design project analysis and evaluation was still a major stage being undertaken in the design process of the student group. However, the presentation stage was now beginning to be integral in the design process of a small number of students ( 2 out of 16). When evaluating this initial change, the data indicated that these two students were those who had continuously used CAD throughout the majority of their design process, with the 'presentation' stage being a period of creating initial renders of their proposed schemes in order to evaluate them. The trend to use both CAD and analogue methods in a singular design stage continued this month with 10 of the 16 students employing this approach for analysis and evaluation of their design (see Fig. 8).

\subsection{Identification of themes: All students - Month 9}

The final month became a period in the design processes studied where the remaining students who were not already engaged in 'production' activities began to rapidly increase production of digital models in order to render their schemes and produce images for the final submission of their design projects. The digital models were used to create the plan, section and elevational outputs of their schemes from a singular dimensional accurate source.

Sections through proposed schemes were produced directly from the CAD allowing alignment of details and sections. The details were created as 'call outs' from the CAD model. During month 9 the students were focused solely on 'production' activities to produce renders and images in readiness for submission. Significantly some students within the group studied 


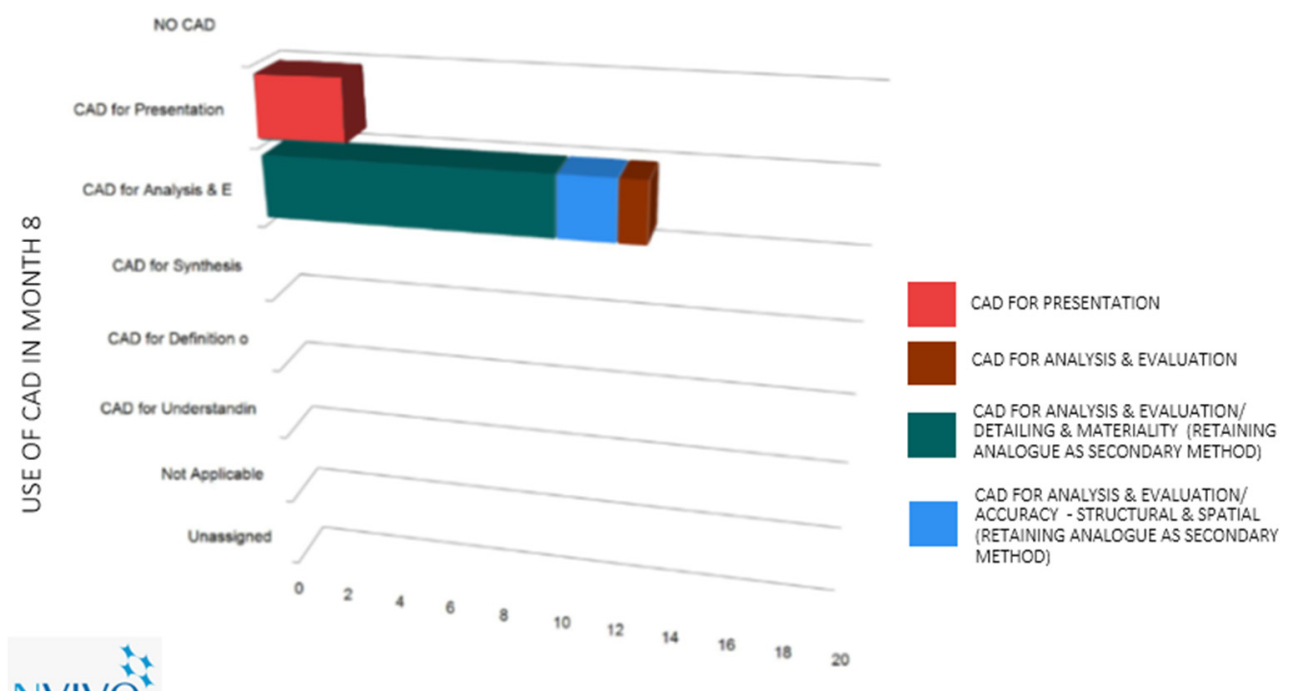

NUMBER OF MATCHING CASES WITHIN STUDY

Figure 8: Comparison of CAD and analogue methods used during month 8.

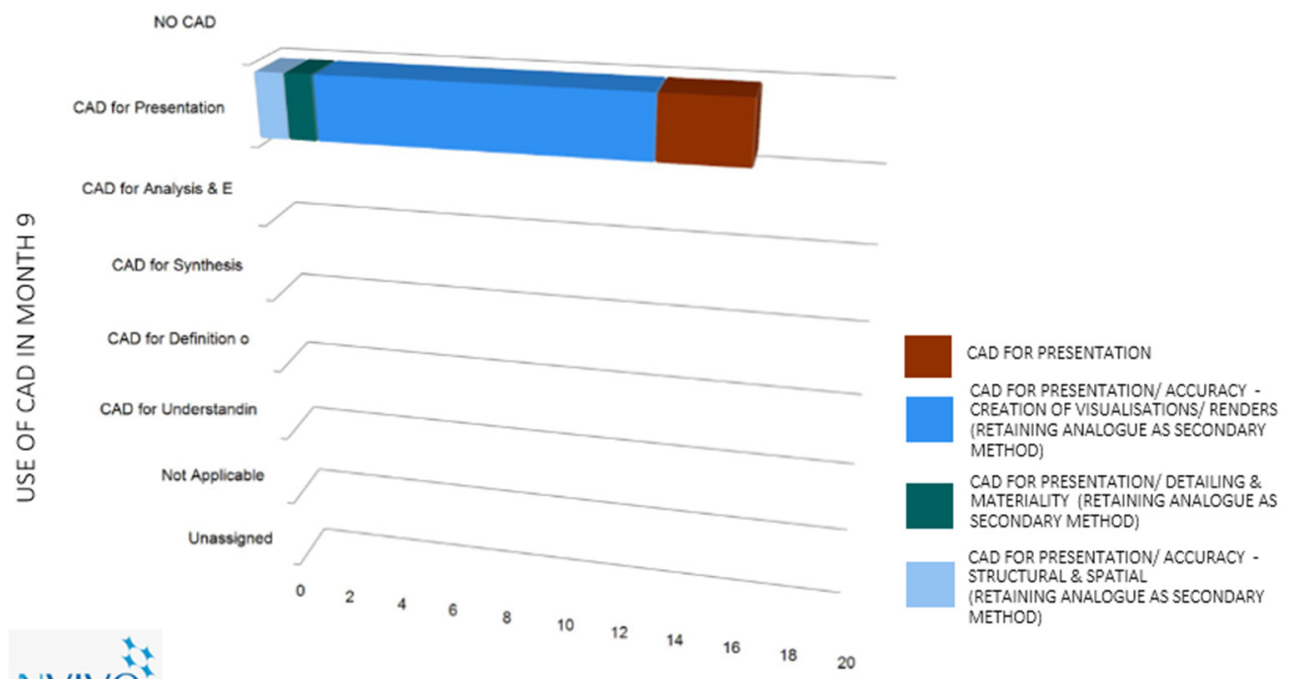

NUMBER OF MATCHING CASES WITHIN STUDY

Figure 9: Comparison of CAD and analogue methods used during month 9.

continued to amend their designs using CAD to enhance visualisation of their schemes during this final month. These final amendments at this late stage in the design process created a period of intense activity where students repeatedly amended digital models to change aspects such as internal lighting in order to 'enhance' the visual appearance of the final images. Technological changes in the proposed design projects were minimal during this 
period for all students in the study, final changes were more for aesthetics, can be seen in Fig. 9.

\section{FINDINGS FROM THE STUDY}

Whilst this study was conducted current studies on the use of CAD have begun to emerge focusing on the outcomes of using CAD in terms of design resolution and transfer of representation of design ideas from manual sketches to digital models. Before the findings are discussed in detail it is important to situate this study's findings in relation to existing literature.

One of the most unexpected findings of this study was the relegated way in which CAD was used in the design process. With the majority of the 16 students studied using CAD as a re-presentation method of that focused more on the visualisation and presentation of a design ideas rather than refinement of the idea through several iterative cycles.

Extant literature suggests that CAD can be used productively to explore a design idea at multiple scales in a highly accurate environment. The findings of Haliburton et al. [21] suggested that using CAD in the design process allows the student to explore their design ideas to levels of detail not afforded by more conventional methods such as sketching. Later research by Ambrose and Fry [22] concluded that the use of BIM in the design process would allow more integrated thinking of a design problem in order to consider material, structure and environmental factors in parallel with the overall design goal. Ambrose championed the instantaneous testing of design solutions using BIM allows a richer understanding of design solutions in the design via exploration of the virtual building model. His studies indicated that analysis in the design process using BIM would develop skills, not hinder them and remove the concern that other academics and researchers have of students becoming mere operators of BIM. However, this study indicates that CAD and BIM remain more of a visualisation device that design solution method.

Previous studies, considered in the literature review, have been empirical in their method of analysis with the objective of finding a universal schema to the design process that all students adhere. Historical research completed by experts in the field of CAD use on architectural design and associated theories of design such as Schon, Bruner, Dubberly, Lawson, Robertson and Allen amongst others referred to in this study have suggested that students studied navigate individual approaches that are underpinned and guided by knowledge and skillsets obtained previously and refer to these as the students 'learning styles'. Few of these historical studies have focused on mode of approach (analogue or digital) and the activities used in the design process. The completion of an activity in the design process creates a form of learning as the new knowledge is attained through a sequence of observation, inquiry, and reflective phases. The outcome is often considered by the student but rarely is the process that led to this learning.

\section{CONCLUSIONS}

The design process as a theoretical construct is contested in the literature. There is extensive debate regarding what activities comprise it, and in what order they are undertaken. Designers often move between and return to previous stages; what Bruner calls spiralling [23]. Generally, the design process follows this format: concept/ideation, scheme design, design development, detail design, communication [24]. Within these stages a designer would be likely to sketch, draw, paint, draft, sculpt, model make, model on the computer, etc. as singular activities and in combination. However, there is also recognition that there are cognitive processes that run concurrent to these activities that can consciously and subconsciously aid or inhibit the design process [25]. Each designer undertakes a different 
process and developing a preference for particular activities over others [26]. The creative design process in architecture is not a linear or didactic, but cyclical and iterative [27].

There is an inextricable link between creativity and the design process; indeed, the design process has been referred to as the engine of creativity [27]. Those students who understand how best to navigate and construct their design process are more likely to operate creatively [28]. The importance of education in developing creativity has been stressed by many commentators [29]-[31], new thought suggests that there may be value in exploring the processes and methodologies in architectural design education to increase the likelihood of creative design outcomes [32]. There is very little investigation on the design process in architecture. In the past architectural design was seen as some sort of language that could be taught based on the use of proportion and archetypal forms. This approach was perhaps satisfactory in a past, however, in the modern era, this could be considered anachronistic, with society requiring architecture with a complexity of form. This also includes use of increased scales during the design process and designing with technical requirements that were not required in the past.

In the modern era, with the invention and subsequent use of digital technologies, the design process has become even more difficult to conceptualise and define. Therefore, students of design subjects are even more likely to find it difficult to navigate through their design process to a successful outcome. Educators are not always equipped to help, having often been educated to use analogue methods [33]. There is thought that designing on the computer may involve different cognitive processes to that of analogue methods [34]. It has been argued that the computer has aided an architect's ability to operate creatively [35] others are far less positive, especially in the educational environment [36] referring to a study undertaken in the US, concluded that students found it 'far more difficult and less interesting to learn from the screen than through analogue methods, such as drawings and physical model making'. It is therefore difficult to fully comprehend the impact of the computer on the design process generally. The computer undoubtedly speeds up certain activities, especially those that are repetitive, while there is a suggestion that the computer may inhibit the creative process required to advance a design project [37]. Designing is a very specific activity that resides within concepts of praxis. In theoretical terms, praxis is our capacity to analyse ideas, apply, make and develop them, while simultaneously reflecting as we are doing. In an educational setting, this natural way of thinking and doing is considered vitally important, especially within the creative disciplines. The effects that the computer has on design-specific praxis have not yet been considered in any depth in extant literature. However, what discussion there is suggests that it may well disrupt this natural process [38].

It has been argued that existing Computer Aided Design (CAD) packages are not conceived for designing in a learning environment (or operating creativity), but are aimed at professional practice as a production tool [39]. The use of such 'production tools' results in good design skills being replaced with good computer skills [40]. This is despite the word design appearing in the title (CAD). This type of software is extremely powerful and persuasive and there is concerned raised by educationalists that if it is introduced too early in an architect's education, or at the wrong stage of a project, then it could inhibit the design process thus resulting in a more linear approach to designing [41], [42]. It is also recognised that a students' creativity is often limited to their knowledge of the software with those who can exploit the software's full potential tend to operate more creatively than those with limited knowledge. In this case the possibilities and the potential of praxis is very much constrained by an inability to properly use the computer.

In conclusion, the extant research on the use of CAD/BIM in the design process is focused on skills and activities within that are or have been augmented by the use of CAD. When 
considering the use of $\mathrm{CAD}$ in the architectural design process the extant research is considerably smaller in scale and written by a limited number of researchers, some of which have been noted in this chapter. Therefore, this study will observe and map the entire design process of a selected group of students, in order to understand how and where CAD activities occurred and what are the effects of CAD being exploited in these design processes. Potential patterns and occurrences will then be categorised and assessed in order to suggest a digital framework to tutors teaching in this subject.

\section{NOTE}

The term computer-aided design (CAD) has now been used within architectural design for over three decades. The use of this software allows the designer to accurately represent floorplans and sections in a dimensionally accurate digital environment. This digital approach of the design process has evolved, and the use of Building Information Modelling (BIM) has become the successor to CAD. The term 'Building Information Model' first appeared in 1992, in a published paper by van Nederveen and Tolman. In this paper the terms 'Building Information Model' and 'Building Information Modelling' (became the acronym BIM). However, BIM did not become more widely used until a decade later in the early 2000s.

The use of CAD is no longer the only digital option for design work, with BIM becoming increasingly used as a collaborative environment tool that has proven to be increasingly important in the design of buildings. The two terms CAD and BIM can be readily confused as they both involve the use of a digital model in the design process. However, these similarities do not mean that they are essentially the same instrument. The use of CAD transfers the lines on paper to lines on a screen, these do not have any values or attributes. When using BIM the digital model is made of components, not lines as in CAD. These components have attributes that allow the model to be used to test aspects of the design in real world conditions, essentially allowing the model to be used to test design solutions in a virtual environment that can accurately assess heating, cooling, and other such environmental factors of a proposed building design.

To ensure clarity, as CAD and BIM are both digital approaches to design exploration in the design process, these acronyms are considered the same for the purpose of this study. When specific software is being discussed the terms CAD or BIM will be used to specifically reference those software approaches.

\section{REFERENCES}

[1] Lonna, F.C., Pérezgómez, A. \& Pelletier, L., Prelude. Mapping the question: The perspective hinge. Architectural Representation and the Perspective Hinge, MIT Press: Cambridge, pp. 2-87, 1997.

[2] Lawson, B.R., Design in architecture. Architecture and the Human Sciences, ed. G. Broadbent, John Wiley and Sons Inc.: London, 1980.

[3] Till, J., Architecture Depends, MIT Press: Cambridge MA, 2009.

[4] Vasudevan, C. \& Tirumala, R., Digital representation of physical artefacts: The effect of low cost, high accuracy $3 \mathrm{~d}$ scanning technologies on engineering education, student learning and design evaluation. ASME 2013 International Design Engineering Technical Conferences and Computers and Information in Engineering Conference. American Society of Mechanical Engineers Digital Collection, 2014.

[5] Snodgrass, A., Coyne, R. \& Martin, D., Metaphors in the design studio. Journal of Architectural Education, 48(2), pp. 113-125, 1994. 
[6] McVeigh, T. \& Paton-Walsh, N. Computers kill pupils' creativity. The Observer, Sep. 24. http://education.guardian.co.uk/news/story/0,372428,00.html. Accessed on: Nov. 2020.

[7] Garber, R., BIM Design: Realising the Creative Potential of Building Information Modelling, John Wiley \& Sons, 2014.

[8] Paszkowski, Z.W. \& Gołębiewski, J.I., International design workshops as an intensive form of architectural education. World Transactions on Engineering and Technology Education, 18(1), pp. 51-56, 2020.

[9] Lawson, B., How Designers Think, Routledge, 2006.

[10] Thurlow, L. \& Ford, P.B., Ideal ideation: A framework for the management of sketch inhibition among undergraduate designers, 2018.

[11] Friedman, D.S., Architectural education and practice on the verge, American Institute of Architects: Report on Integrated Practice, eds M. Broshar, N. Strong \& D.S. Friedman, The American Institute of Architects: Washington, DC, pp. 3-7, 2006.

[12] Shelbourn, M., Macdonald, J., McCuen, T. \& Lee, S., Students' perceptions of BIM education in the higher education sector: A UK and US perspective. Industry and Higher Education, 31(5), pp. 293-304, 2017.

[13] Lawson, B., Towards a computer-aided architectural design process: A journey of several mirages. Computers in Industry, 35(1), pp. 47-57, 1998.

[14] Taleyarkhan, M., Dasgupta, C., Garcia, J.M. \& Magana, A.J., Investigating the impact of using a CAD simulation tool on students' learning of design thinking. Journal of Science Education and Technology, 27(4), pp. 334-347, 2018.

[15] Abdirad, H. \& Dossick, C.S., BIM curriculum design in architecture, engineering, and construction education: A systematic review. Journal of Information Technology in Construction (ITcon), 21(17), pp. 250-271, 2016.

[16] Ambrose, M., Agent provocateur: BIM in the academic design. International Journal of Architectural Computing, 10(01), pp. 53-66, 2012.

[17] Ambrose, M.A. \& Fry, K.M., Re-thinking BIM in the design studio. 6th ASCAAD Conference, p. 71, 2012.

[18] Dainty, A., Methodological pluralism in construction management research. Advanced Research Methods in the Built Environment, 1, pp. 1-13, 2008.

[19] Grix, J., Social capital as a concept in the social sciences: The current state of the debate. Democratization, 8(3), pp. 189-210, 2001.

[20] Gray, D.E., Doing Research in the Real World, SAGE, 2013.

[21] Haliburton, J., Clayton, M., Ozener, O. \& Francisco Farias, W.J., Parametric modelling and BIM: Innovative design education for integrated building practices, 2011.

[22] Ambrose, M.A. \& Fry K.M., Re: Thinking BIM in the design studio-beyond tools... approaching ways of thinking, 2012.

[23] Bruner, J., The Process of Education, Harvard University Press: Cambridge, MA, 1960.

[24] Goldschmidt, G. \& Sever, A.L., Inspiring design ideas with texts. Design Studies, 32(2), pp. 139-155, 2011.

[25] Lawson, B., How Designers Think: The Design Process Demystified, Routledge: London, 2006.

[26] Goldschmidt, G., On visual design thinking: The vis kids of architecture. Design Studies, 15(2), pp. 158-174, 1994.

[27] Kowaltowski, D., Methods that may stimulate creativity and their use in architectural design education. International Journal of Technological Design Education, 20(3), pp. 453-476, 2010. 
[28] Casakin, H., Associative thinking as a design strategy and its relation to creativity. DS 68-7: Proceedings of the 18th International Conference on Engineering Design (ICED 11), Impacting Society Through Engineering Design, Vol. 7: Human Behaviour in Design, Lyngby, Copenhagen, Denmark, 15-19.08.2011, 2011.

[29] Amabile, T., The Social Psychology of Creativity, Springer-Verlag: New York, 1983.

[30] Robinson, K., All Our Futures: Creativity, Culture and Education, National Advisory Committee: Suffolk, 1999.

[31] Cox, A., What are communities of practice? A comparative review of four seminal works. Journal of Information Science, 31(6), pp. 527-540, 2005.

[32] Cropley, A.J., Creativity in Education and Learning, A Guide for Teachers and Educators, Kogan Page: London and Sterling, USA, 2001.

[33] Till, J., Architecture Depends. MIT Press: Cambridge, MA, 2009.

[34] Vasudevan, C. \& Tirumala, R., Digital representation of physical artefacts: The effect of low cost, high accuracy 3D scanning technologies on engineering education, student learning and design evaluation. ASME 2013 International Design Engineering Technical Conferences and Computers and Information in Engineering Conference. American Society of Mechanical Engineers Digital Collection, 2014.

[35] Snodgrass, A., Interpretation in Architecture, Routledge: New York, 2006.

[36] McVeigh, T. \& Paton Walsh, N., Computers kill pupils' creativity, 2000. http://education.guardian.co.uk/news/story/0,,372428,00.html. Accessed on: 21 Apr. 2021.

[37] Vasudevan, C. \& Tirumala, R., Digital representation of physical artefacts: The effect of low cost, high accuracy 3D scanning technologies on engineering education, student learning and design evaluation. ASME 2013 International Design Engineering Technical Conferences and Computers and Information in Engineering Conference. American Society of Mechanical Engineers Digital Collection, 2014.

[38] Bonnardel, N. \& Zenasni, F., The impact of technology on creativity in design: an enhancement? Creativity and Innovation Management, 19(2), pp. 180-191, 2010.

[39] Radclyffe-Thomas, N., White heat or blue screen? Digital technology in art \& design education. International Journal of Art \& Design Education, 27(2), pp. 158-167, 2008.

[40] Lawson, B., How Designers Think: The Design Process Demystified, Routledge: London, 2006.

[41] Brown, M., The teacher-tool relationship: Theorizing the design and use of curriculum materials. Mathematics Teachers at Work: Connecting Curriculum Materials and Classroom, ed. Remillard, Routledge: New York, pp. 17-36, 2009.

[42] Robertson, J. \& Nicholson, K., Adventure author: A learning environment to support creative design. Proceedings of the 6th International Conference on Interaction Design and Children, ACM, pp. 37-44, 2007. 